\title{
Discrimination In Organizations: An Organizational-Level Systems Perspective
}

Michele J. Gelfand

Lisa H. Nishii

Jana L. Raver

Benjamin Schneider

Working Paper 07 - 08 


\title{
Discrimination In Organizations: An Organizational-Level Systems Perspective
}

\author{
Michele J. Gelfand \\ Department of Psychology \\ University of Maryland \\ Lisa H. Nishii \\ Human Resource Studies \\ School of Industrial and Labor Relations \\ Cornell University \\ Jana L. Raver \\ University of Maryland \\ Personnel Research Associates, Inc. \\ Benjamin Schneider
}

March 2007

http://www.ilr.cornell.edu/cahrs

This paper has not undergone formal review or approval of the faculty of the ILR School. It is intended to make results of Center research available to others interested in preliminary form to encourage discussion and suggestions.

Most (if not all) of the CAHRS Working Papers are available for reading at the Catherwood Library. For information on what's available link to the Cornell Library Catalog:

http://catalog.library.cornell.edu if you wish. 


\section{Abstract}

Chapter to appear in R.L. Dipboye and A. Colella (Eds.), Psychological and Organizational Bases of Discrimination at Work. Jossey-Bass Frontiers Series.

AUTHORS' NOTE: We thank the editors of this volume for their very helpful suggestions and insights.

Please Do Not Cite Or Quote Without Permission 


\section{Discrimination In Organizations: \\ An Organizational-Level Systems Perspective}

It has become increasingly clear to organizational decision makers that employment discrimination is a serious and expensive problem that needs to be addressed. For instance, in 2000 Coca-Cola Co. settled a class-action racial discrimination lawsuit for $\$ 192.5$ million, which was preceded by Texaco Inc.'s settlement for \$176.1 million and Shoney's Inc.'s settlement for $\$ 132$ million (King \& Spruell, 2001). In fact, the financial costs associated with discrimination settlements extend beyond the costs of the actual settlement to include negative stock price changes, presumably due to investor perceptions that discriminating firms may have less talented and committed workforces, high operating costs due to turnover, absenteeism, and job dissatisfaction, poor reputations with diverse customers, and/or lower organizational adaptability (Wright, Ferris, Hiller \& Kroll, 1995).

At the same time, there have been some genuine advances, where traditional monolithic (unicultural) organizations have been transformed into more multicultural (Cox, 1994) environments. For instance, after Denny's parent company, Advantica Restaurant Group, Inc., settled a racial discrimination lawsuit for $\$ 54.4$ million in 1994 , they made organization-wide changes towards increasing diversity, and by 1998, the company was listed on Fortune magazine's list of the best U.S. companies for Asians, African Americans, and Hispanics, and has remained near the top of that list since then (Hickman, Tkaczyk, Florian, Stemple \& Vazquez, 2003). Similarly, Coca-Cola made widespread changes immediately following the 2000 discrimination settlement, and has now also been named a top U.S. company for racial minorities (Hickman et al., 2003). While such rankings do not necessarily reflect genuine cultural changes (Prasad, Mills, Elmes \& Prasad, 1997), the apparent success of these corporations in dealing with discrimination highlight several organizational-level factors that may predict discrimination. These organizational-level antecedents to discrimination are the focus of this chapter. 
In what follows we present a systems model, summarized in Figure 1, of discrimination at the level of the organization. We elaborate the model shown in Figure 1 and illustrate the ways in which aspects of organizations - including formal and informal structure, organizational culture, leadership, strategy, human resource systems, and organizational climates - may contribute to or attenuate discrimination. As depicted in Figure 1 and as discussed in detail in previous chapters, the relationship between these organizational-level processes and actual levels of discrimination is necessarily mediated by individual cognitions and interpersonal behaviors. Furthermore, we recognize that organizations do not exist in a vacuum but rather they exchange resources and information with the environment. To fully attend to the implications of this point, we utilize an open-systems model of organizations (Katz \& Kahn, 1978) to briefly discuss inputs from the environment and organizational outputs to the environment. Thus, we begin below with a brief overview of environmental factors such as the legal, economic, and social environment that serve as inputs into the organization that are relevant to the phenomenon of discrimination. Then, the major section of the chapter is devoted to a detailed analysis of the existing literature on discrimination at the level of the organization. This exploration is accomplished through examination of six different organizational throughputs: organizational structure, organizational culture, leadership, strategy, HR systems, and organizational climate. We then briefly discuss some of the outcomes associated with organizational discrimination and the ways in which these outputs are then fed back into the environment in which organizations function. Finally, we conclude with future directions for the study of discrimination at the organizational level. 
Figure 1

A Model of Discrimination At The Level Of The Organization

\section{INPUTS}

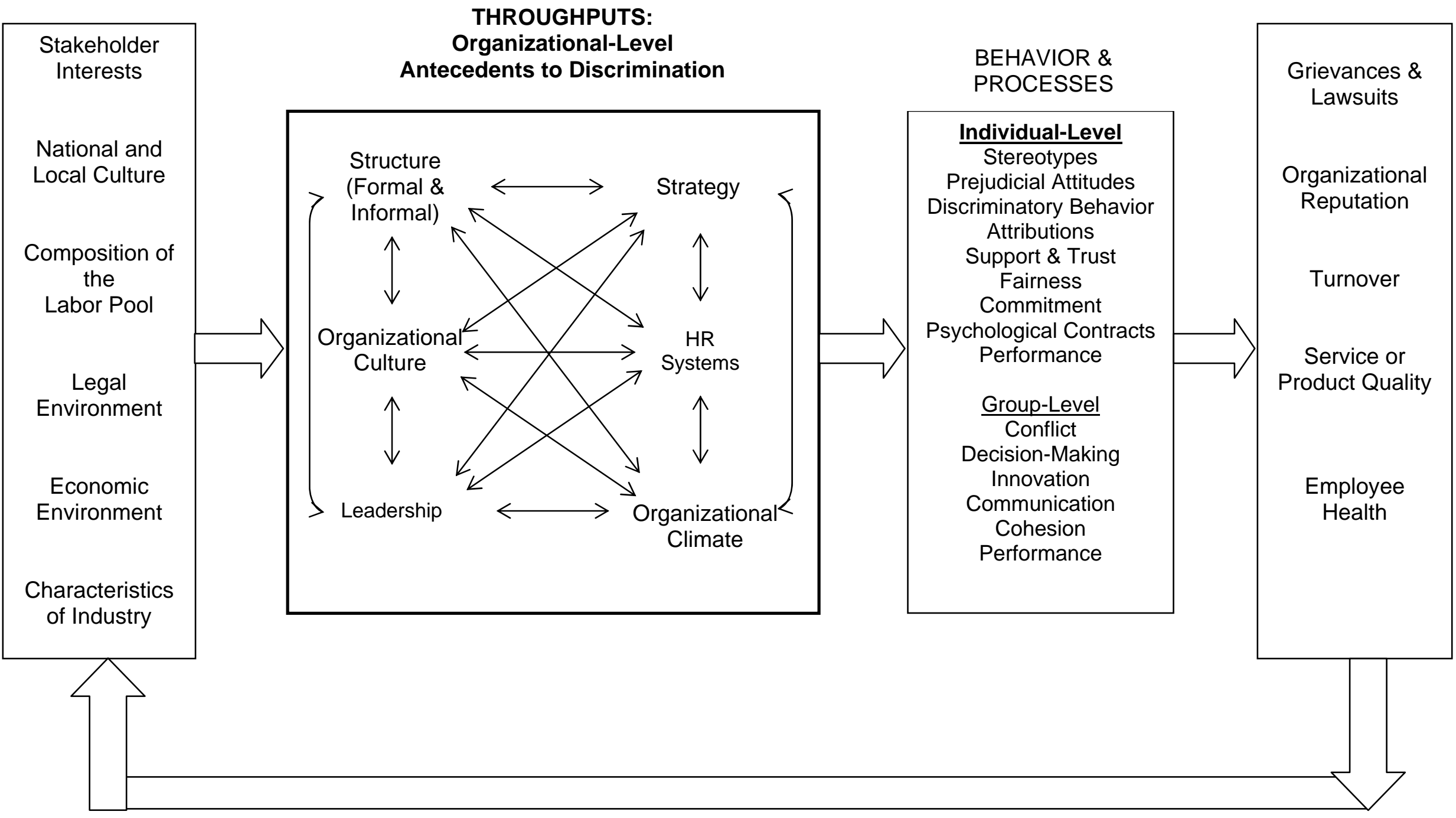

\section{OUTPUTS}

THROUGHPUTS:

Organizational-Leve Antecedents to Discrimination 


\section{Influence of the Organization's Larger Context}

Organizations, as systems, function within the larger context in which they exist.

Environmental inputs into organizations can have a marked impact upon the types of behaviors, processes and structures that are enacted within the organization. In this section, we briefly discuss a number of inputs from the environment into the organization system that influence the levels of discrimination that might emerge (see chapter $X X$ for more information on societal and contextual factors that influence discrimination in organizations). We do not mean to suggest that these inputs from the environment of the organization always or even likely yield discrimination as we discuss it later in the chapter. However, what is important to understand is that organizations existing in specific contexts have an increased probability of engaging in discriminatory behaviors due to these contextual issues.

First, national culture influences the extent to which discrimination will occur in organizations, particularly due to cross-cultural variability in the extent to which discrimination against certain groups is codified in cultural norms (House, Hanges, Javidan, Dorfman \& Gupta, in press; The World Values Survey, 1994). In addition, local norms and sociocultural legacy with respect to prejudice may influence people's propensity to discriminate within organizations in those communities (Cox, 1994). ${ }^{1}$ In addition, the legal environment in which organizations operate affect both experiences of discrimination as well as attention that is paid to discrimination-related issues by organizations and their employees. For example, the design and implementation of HR practices in U.S. companies are constrained by a variety of employment laws which collectively prohibit discrimination on the basis of race, color, religion, sex, national origin, age, and disability (Ledvinka \& Scarpello, 1991), and additional employment laws in some states prohibit discrimination on the basis of sexual orientation (Jackson \& Schuler, 2003).

The policies, practices, and strategies that organizations adopt are also strongly influenced by the interests of the organizations' stakeholders, which include customers, professional 
organizations, government agencies, labor unions, stockholders, and suppliers/vendors, among others (Donaldson \& Preston, 1995). For example, pressure from professional organizations, government agencies and union contracts tends to lower discrimination in organizations (Blum, Fields, \& Goodman, 1994; Perry, Davis-Blake, \& Kulik, 1994; Delaney \& Lundy, 1996).

Economic conditions may influence an organization's willingness to devote attention and resources to combating discrimination (Kahn, 2001). For example, compared to conditions of low threat, under conditions of threat (e.g., recessions, downsizing), organizations are more likely to become rigid, relying on a limited set of well learned and habituated behavioral scripts, and focusing on business issues that are of core strategic importance (Staw, Sandelands, \& Dutton, 1981). Moreover, the degree to which organizations feel pressured to integrate diverse workers may be influenced both by industry-based norms (i.e. the diversity-related practices of peer organizations) as well as by the demographic characteristics of a particular industry (DiMaggio \& Powell, 1983).

\section{The Influence of the Organization's Internal Context}

The environmental factors discussed above all feed into the organization, which is comprised of several interdependent processes systems and structures. Of particular interest in this chapter are the six organizational-level antecedents to discrimination depicted in Figure 1 i.e., formal and informal structure, organizational culture, leadership, strategy, HR systems, and organizational climate. The identification of six major throughputs in no way implies that these are independent of each other. On the contrary, as Figure 1 shows, these interact with each other; identifying them as separate is merely for convenience of exposition.

\section{Structure}

Formal Structure. Perhaps the most widely publicized form of discrimination in organizations is the "glass ceiling," which refers to the invisible barrier that blocks women and racial minorities from advancing to senior leadership positions in organizations (i.e., access discrimination). There is substantial evidence suggesting that women and racial minorities are 
underrepresented in upper management. For instance, women make up only $34 \%$ of "officials and managers" in U.S. corporations, whereas they constitute $47 \%$ of the private workforce. Also concerning are the low numbers of racial minorities in management, where only $15 \%$ of "officials and managers" are members of a minority group, yet they constitute $30 \%$ of the private U.S. workforce (U.S. Equal Employment Opportunity Commission, 2001). A study comparing data from 1995 and 2000 found that the status of women in management has not improved in recent years (U.S. General Accounting Office, 2002), where women held a share of all management jobs proportionate to their share of the industry workforce in only half of the industries studied. These statistics are unsettling when one considers that women and minorities constituted $63 \%$ of the private U.S. labor force in 2001 (USEEOC, 2001), and that the projected rates of participation in the labor force are expected to grow three to six times as fast for racial minority groups than for white non-Hispanics (U.S. Bureau of Labor Statistics, 1999).

Structural integration, or diverse representation at senior management levels, is an important consideration not only because it is a symptom of the level of discrimination in an organization (Bennet, 2002; James, 2000) but because it is also an antecedent of further discrimination. Segregation perpetuates itself because of "homosocial reproduction," where individuals hire and promote those who are like themselves, thereby resulting in fewer opportunities for individuals who are different from the people in power (Kanter, 1977; Perry et al., 1994; Ragins \& Sundstrom, 1989). Furthermore, a lack of diverse representation at high levels makes it more likely that the organizational culture is monolithic (Cox, 1994) or defined by cultural norms associated with white, heterosexual, able-bodied males who have access to powerful others (i.e., the dominant coalition; Brass, 1985). In such organizations, non-traditional employees often feel pressure to assimilate rather than being free to be themselves. Moreover, organizations that have diverse representation at the top and throughout the organization are less likely to have employees who rely on stereotypes in their social interactions (Perry et al, 1994). This is based on the notion that such employees are able to develop more idiosyncratic 
schemas for other individuals because of a balanced exposure to diverse people. Of course, increasing representation above the glass ceiling is not the only goal for organizations seeking to reduce discrimination; building a critical mass of diverse workers throughout the organization can also be an effective deterrent to discrimination (Arvey et al., 1996).

In addition to the structural integration of racial minorities throughout an organization, other aspects of organizational structure relate to discrimination within organizations. Bureaucratic organizations characterized by formal job ladders tend to perpetuate gender discrimination because job ladders are typically segregated by gender, with women's ladders offering fewer opportunities, less visibility and lower pay (Perry et al., 1994). Large companies may have greater levels of discrimination because of stable and unchanging employment conditions, whereas small, growing companies hire and promote with greater frequency and are in a better position to reduce access discrimination and reshape the demographic composition of their workforces (Arvey et al., 1996). Large companies also tend to have greater specialization of labor, a proliferation of titles, narrow spans of control, and lengthy chains of command. In addition to facilitating segregation, these characteristics decrease discretion by making it more likely that behaviors are closely monitored (Kelley, 1993). Deviations from the norms of the dominant coalition may be less acceptable and non-majority group members' diverse approaches to work tasks less likely to be encouraged (Oerton, 1994). The existence of a formal diversity or EEO officer also has implications for discrimination. The diversity officer has an important role in reengineering HR systems to avoid discriminating against those who do not "fit" (Arvey, et al., 1996), and when the diversity/EEO officer is highly paid relative to other administrators, the officer is seen as powerful within the organization and employees perceive that the organization is committed to eliminating discrimination (Perry et al., 1994; Morrison \& Von Glinow, 1990).

Informal structure. The patterns of interpersonal relationships in organizations also play an important role in organizational discrimination. Racial minorities often lack access to informal 
social networks in organizations because participation in informal groups is influenced by sociocultural similarity or "homophily" (Ibarra, 1993). Similarly, women tend to belong to gender-segregated networks within organizations (Brass, 1985). The result of segregated networks is that women and racial minorities tend to be less central to the networks of the dominant coalition and hence receive fewer favorable organizational outcomes such as access to information about jobs, organizational status, and mobility (Ragins \& Sundstrom, 1989; Seidel, Polzer, \& Stewart, 2000). Moreover, due to the fact that most high-ranking positions in organizations are still held by white males, women and racial minorities are at a disadvantage when it comes to finding a mentor who can offer instrumental or career-related support and access (Burke, McKeen, \& McKenna, 1993; Tsui \& O’Reilly, 1989; Whitely, Dougherty, \& Dreher, 1991). When women and racial minorities do find mentors, the mentor relationships tend to provide a narrower range of benefits and are more difficult to manage successfully (Kram, 1985; Thomas, 1993).

\section{Organizational Culture}

Traditional approaches to eliminating discrimination have typically focused on recruiting and hiring increased numbers of nontraditional employees (Gottfredson, 1992; Jackson, 1992), but have stopped short of emphasizing the elimination of more subtle forms of discrimination in organizations, such as in an organization's basic assumptions and values, or culture (Carnevale \& Stone, 1995; Triandis, Kurowski \& Gelfand, 1994). The concept of organizational culture has been referred to as the "personality" of an organization, which is typically defined by shared values, common understandings, and patterns of belief and expectations, which are often takenfor-granted (Gagliardi, 1986; Sathe, 1985; Schein, 1985) and manifested in many different ways, such as in actual patterns of behavior (Sathe, 1985), organizational climates (Schneider, 2000), and material artifacts such as office arrangements and dress (e.g., Peters \& Waterman, 1982). 
Culture content. Organizational cultures are not neutral with regard to what types of employees fit and which employee behaviors are valued. Organizational leaders hold stereotypes with regard to which types of employees are best and they tend to reward employees who behave most consistently with their stereotypes (Ilgen \& Youtz, 1986). Such discriminatory cultural beliefs, values and assumptions may be manifested in cultural artifacts such as behavioral norms, HR practices, and physical arrangements. Cox (1994) provided numerous examples, including the practice of scheduling fifty-hour-plus workweeks and evening meetings, valuing and promoting employees with high verbal fluency (e.g. polished English in presentations, input during meetings, self-confident speech patterns), and lack of wheelchair access despite ADA regulations. In addition, discriminatory cultural assumptions may also be communicated directly through derogatory language referring to nontraditional employees (e.g., "the affirmative action hiree;" Heilman, Block, \& Lucas, 1992), sexual or ethnic harassment (e.g., Schneider, Hitlan \& Rodhakrishnan, 2000), inappropriate jokes (Siehl \& Martin, 1988), backlash attitudes toward diversity-related programs (Morrison, 1992), or business justifications for discriminating (Brief, Dietz, Cohen, Pugh, \& Vaslow, 2000).

Culture strength. When discussing organizational culture, it is also important to address the strength of the culture, or the extent to which organizational members agree about the organization's values, beliefs, assumptions, and norms (Cox, 1994). In strong cultures, there tend to be a preponderance of strong situations that require members to behave according to agreed-upon standards for proper behavior by imposing sanctions if behavior deviates from those standards (Mischel, 1976). At an extreme, strong cultures could result in nontraditional employees needing to conform to the norms of the dominant coalition, and thus experiencing discrimination because their diverse approaches to work are devalued. In contrast, weak cultures are characterized by multiple sets of contrasting norms and values, thereby allowing for greater variability in the behavioral scripts that are deemed culturally appropriate (Mischel, 1976). Yet in a weak culture with no strong situational norms that prescribe how one should 
behave, people may be most likely to invoke their own identities in determining their behavior (Cox, 1994; Mischel, 1977), which could result in a situation where each person is free to act based upon his or her own particular desires or prejudices without regard for organizational priorities (i.e., a fragmented culture; Martin, 2002). Thus, neither a weak nor a strong organizational culture is necessarily an antecedent to discrimination. Rather, the essential consideration is whether the values pertaining to the inclusion of all employees are strong (i.e., the cultural content about diversity and inclusion), while values pertaining to the range of behavioral styles and diverse approaches to work are weak. Organizations that have this particular combination of strong and weak cultural values are those that are likely to be the most successful at eradicating discrimination (Cox, 1994).

\section{Leadership}

Without the full commitment of upper-level leaders in an organization, diversity initiatives are likely to fail and thus discriminatory practices are unlikely to be eradicated (Cox \& Blake, 1991). However, it is also necessary to look below the upper-most levels to examine the ways in which the behaviors and decisions of mid-level management and direct supervisors may also perpetuate discrimination.

Upper-level management. At the highest levels of leadership in organizations, the CEO, the Top Management Team (TMT), and the corporate board are instrumental in determining the direction that the organization will take with regard to diversity and discrimination. Leaders must first recognize the potential for discrimination in traditional organizational practices and structures, and believe in the need to value all employees and remove obstacles to their success (Stoner \& Russell-Chapin, 1997). The CEO and top management team make important decisions regarding organizational strategies and resources, and they communicate the organization's priorities to all members and stakeholder groups (Yukl \& Van Fleet, 1992). The extent to which leaders choose to emphasize inclusiveness in the organization's strategy and the extent to which resources (i.e., personnel, money, time) are devoted to eliminating all 
forms of discrimination are indicators of leaders' priorities, and indicate which "types" of employees are valued (Loden \& Rosener, 1991). Top-level leaders can also discourage discrimination by implementing systems of accountability that make rewards contingent upon meeting diversity goals (Morrison, 1992).

In the case where the corporate board and TMT have decided to pursue an organizational change strategy to increase diverse representation and inclusiveness throughout the organization, the symbolic role of the CEO is particularly important. Cox and Blake (1991) argue that "champions for diversity" are needed to enact change - and the CEO is in a very good position to passionately pursue change, role model the behaviors required for change, and help the organization to move forward (Loden \& Rosener, 1991). Such a leader can help to establish an inclusive organizational culture through persistent communication of and visible support for all programs and policies aimed at reducing discrimination (Stoner \& RussellChapin, 1997). In addition, when successes occur, he or she would provide rewards and retrospective interpretations consistent with the desired values (Gagliardi, 1986; Trice \& Beyer, 1991). In this manner, a CEO who demonstrates commitment to eliminating all forms of discrimination throughout the organization may play a crucial role in transforming an organization from monolithic (or plural) to multicultural (Cox, 1994).

Mid-level management and direct supervisors. While top management serves a symbolic function and makes decisions that affect the organization as a whole, most employees' daily experiences with organizational leaders are with direct supervisors or mid-level departmental (unit) managers. These instrumental leaders interpret organizational strategies, policies, and practices (Zohar, 2000), and therefore act as a "lens" through which employees perceive the organization. Immediate supervisors set the tone for what behaviors are acceptable and what behaviors are not acceptable (Yukl \& Van Fleet, 1992); thus when management fails to punish discriminatory behaviors, employees may assume that such discriminatory actions are acceptable, which then perpetuates such acts. 
Furthermore, mid-level management and supervisors make decisions about access to organizational rewards (e.g., pay, promotions, access to training, performance appraisals, important social networks), and this acts as a proximal determinant of the extent to which discrimination exists in a particular department. As will be described in more detail below, evidence suggests that due to stereotyping, prejudicial attitudes, and the similar-to-me bias, supervisors are more likely to reward those employees who are like themselves (Fadil, 1995; Ilgen \& Youtz, 1986). If most supervisors are white, male, able-bodied, and heterosexual, these negative attitudes and the similarity-attraction effect may lead to systematic biases against those who are different. In other words, personnel decisions (selection, promotion) in a single department may not appear discriminatory, yet in the aggregate across an entire organization where this same process occurs repeatedly, the end result is organizational-level patterns of discrimination.

This may be true with regard to the development of high-quality leader-member exchanges (LMX) as well; they may be less likely to develop between leader-subordinate dyads composed of individuals who are demographically different (Hiller \& Day, 2003). Yet, because LMX relationship quality is thought to be pivotal for the access that subordinates receive to resources, information, important networks, and opportunities, Douglas and his colleagues suggest that leaders who develop high-quality LMX relationships with diverse subordinates are the key to providing opportunities for success and combating discrimination in organizations (Douglas, Ferris, Buckly, \& Duundlach, 2003). Ultimately, those managers who establish high quality LMX relationships with all of their employees without discriminating against minority subordinates will be in a position of competitive advantage, as they will be in a better position to utilize all of their human resources (Douglas, et al., 2003). Indeed, recent empirical evidence provides support for this proposition: Nishii and her colleagues found that departments within an organization with high ingroup racial diversity (i.e., departments in which racial minorities 
reported high quality LMX relationships with their managers) outperformed departments with low ingroup racial diversity in terms of profits (Nishii, Mayer, Goldstein, \& Dotan, 2004).

\section{Strategy}

When strategies for advancing diverse employees and creating a culture of inclusiveness are embedded within an organization's strategic business plan, consequent levels of discrimination tend to be lower (Catalyst, 1993; USDOL, 1995). Actually including EEO as part of a company's business strategy is important because statements of non-discrimination are a very tangible and salient sign that discrimination is not tolerated within an organization (Morrison \& Von Glinow, 1990). Further, publicly stating the importance of diversity as a basis of competitive advantage and human resource quality fosters the belief that diversity represents an opportunity for the organization rather than a problem (Cox \& Blake, 1991).

Although the specific business case for reducing discrimination may differ across organizations or industries, there are several business rationales for being committed to the recruitment, retention and advancement of diverse employees. They include better customeroriented decision making resulting from a better reflection of a company's consumer base within the company's workforce and management (Robinson \& Dechant, 1997); attracting both customers and qualified applicants as a result of gaining a reputation as a good place to work for all types of employees (Cox, 1994); the full utilization of the organization's human capital (Wentling \& Palmas-Rivas, 1997); lower costs due to reduced turnover, absenteeism, and discrimination lawsuits (Jackson \& Alvarez, 1992); and increased workforce productivity and improved organizational health (Jackson \& Alvarez, 1992).

There is also a theoretical basis for expecting that organizations that pursue an innovation strategy will be motivated to capitalize on the diversity of behavioral scripts that results from a diverse workforce (i.e., the value-in-diversity hypothesis; Cox, Lobel \& McLeod, 1991). This is based on the evidenced that diverse groups are more likely to produce a diverse set of ideas compared to homogeneous groups (Milliken \& Martins, 1996) and the wider set of ideas is 
expected to translate into better decisions (O'Reilly, Williams \& Barsade 1998). An organization that perceives the differential competencies and experiential bases of diverse employees as a source of competitive advantage is less likely to engage in practices that discriminate against non-traditional groups.

\section{Human Resource Systems}

Human Resource practices play a critical role in shaping the extent of discrimination that occurs within an organization by influencing the access that employees have to opportunities and valued rewards within the organization (access discrimination) as well as their treatment as organizational citizens (treatment discrimination; Levitin, Quinn \& Staines, 1971). One of the hallmarks of equitable HR systems design is the establishment of objective or formalized criteria for various HR practices, which leads to the elimination of bias and subjectivity in the implementation of HR practices (Delaney \& Lundy, 1996). It is important to emphasize that HR practices work as a system in influencing the level of discrimination that is experienced within an organization—disproportionate opportunities or biased treatment in one area (e.g. access to mentoring, training) can have ripple effects in other areas of functioning (e.g. promotion) within an organization.

Recruitment and Selection. Affirmative Action Programs (AAPs) are aimed at eliminating employment discrimination against women and racial minorities and to redress the effects of past discrimination within an organization. In a review of the literature, Kravitz and his colleagues (1996) concluded that white males respond more negatively to AAPs than other demographic groups, and women generally have more positive attitudes than men. In addition, reactions to AAPs are more favorable when attention to demographic status is given during recruiting stages as compared to the final stage during which selection decisions are made (Kravitz et al., 1996). Thus, while AAPs may help to alleviate initial access discrimination, they may create stigmas (Heilman et al., 1992) that exacerbate problems related to treatment discrimination. Methods of combating discriminatory perceptions that might result from AAPs 
involve providing justifications for the adoption of AAPs and providing clear and compelling evidence of the target members' competence (Biernat \& Kobrynowicz, 1997; Kravitz et al., 1996).

The extent of discrimination that occurs during the recruiting process depends on the channels that are used to recruit applicants. The U.S. Department of Labor found that organizations that actively recruit at minority/female-oriented colleges and universities evidence lower levels of discrimination (USDOL, 1995). When engaging in such targeted recruitment strategies, organizations might consider showcasing their diversity efforts in their recruiting materials, due to the evidence that candidates with strong ethnic identities are more attracted to organizations that explicitly make reference to their diversity initiatives than those that do not (Kim \& Gelfand, 2003). In comparison to organizations that engage in targeted recruiting, organizations that rely on informal networks to fill open positions (both from internal and external labor markets) may increase the probability of discriminating against groups who often do not have equal access to the social networks that are connected to jobs (Braddock \& McPartland, 1987; Ragins \& Sundstrom, 1989).

With regard to selection procedures, much is known about the discriminatory impact of various selection instruments. The best way to combat discrimination is to use selection measures that tap as many aspects of job performance as possible, utilize different media in terms of the ways in which content is presented and responses are required (oral, video-based, and behavioral media exhibit lower adverse impact than written ones), and use noncognitive measures such as personality and integrity tests when possible (Campion et al., 2001). In addition, interviews tend to result in lower group differences, although the structuring of interviews and interviewer training to reduce cognitive biases are both important for minimizing adverse impact (Conway, Jako, \& Goodman, 1995; Hough, Oswald \& Ployhart, 2001). In sum, research on adverse impact clearly indicates that the continued use of only paper and pencil measures of cognitive ability as a basis for access decisions is unwarranted-and will likely be 
perceived as unfair by applicants, especially when the job relevance of the measure is not transparent (Ryan \& Ployhart, 2000).

Performance management. There are two main issues involving discrimination in performance appraisal systems, namely removing bas in the evaluation process itself and ensuring that performance evaluation and reward systems reinforce the goal of managing diversity and eliminating discrimination in the workplace (Cox, 1994). Performance management systems that involve explicit performance expectations, clear performance standards, accurate measures, and reliable performance feedback, as well as the consistent application of these standards across ratees help to reduce the chances of discriminatory ratings (Bernardin, Hagan, Kane, \& Villanova, 1998; Klimoski \& Donahue, 1997; Morrison \& Von Glinow, 1990). While clear expectations are important for minimizing subjectivity and the potential for discrimination within the performance management process, performance norms should permit some latitude for expressing individuality and should not be arbitrarily based on a singular cultural perspective (Delaney \& Lundy, 1996). Utilizing outcome-based performance measures rather than process-based performance measures may help minimize discrimination because the former allow for equifinality in the way that tasks are accomplished on the job (Kelley, 1993), thereby reducing the probability that certain behavioral styles (that might be correlated with group membership) are preferred over others.

The unbiased implementation of performance management systems also requires that the feedback process be formalized and consistently enacted so that all employee groups receive developmental feedback. Otherwise, women might be less likely to receive critical feedback from managers who hold stereotypical beliefs about the likelihood that women might respond emotionally to critical feedback, or racial minorities might be disadvantaged by managers who are afraid of providing them with critical feedback for fear of appearing prejudiced. Receiving critical feedback and opportunities for challenging assignments are essential to performance for all employees; not receiving such opportunities can cause minority employees to lag behind 
white males in their career development and experience further discrimination, what Ilgen and Youtz (1986) aptly termed "the lost opportunities effect". Indeed, the differential expectations of employee ability on the part of supervisors can have pervasive effects on employee performance and thus can be an important source of discrimination in organizations. Research has shown, for example, that low leader expectations are associated with self-fulfilling prophecies, and low levels of performance (the "Golem effect," Davidson \& Eden, 2000), while high expectations are associated with enhanced performance (Pygmalion effect, Dvir, Eden, \& Banjo, 1995). Low expectations may be particularly problematic for employees in jobs that are incongruent with sex-role or racial stereotypes (Nieva \& Gutek, 1980).

Finally, performance goals that are explicitly geared toward enhancing managerial accountability in reducing discrimination are associated with lower levels of discrimination (USDOL, 1995). Supervisor supportiveness of diversity and family issues can be assessed through the use of upward feedback mechanisms, with recognition provided to managers who provide creative and sensitive solutions to managing diversity (Lobel \& Kossek, 1996).

Training. There are two forms of training that are important to discuss here, diversity training and competency training. The primary objectives of most diversity training programs are to increase awareness of diversity issues, reduce stereotypes and biases about the suitability of diverse workers for career success, and provide employees and managers with the skills necessary to interact effectively with diverse others (Hanover \& Cellar, 1998; Wentling \& Palmas-Rivas, 1997). In addition to diversity-specific training, the availability of career development training for diverse employees is an important antecedent of discrimination in that it influences the effectiveness with which diverse employees can compete for promotions within organizations. Organizations that institute succession planning or fast-track development programs, in which qualified employees with management potential are identified and properly trained, exhibit lower levels of discrimination (USDOL, 1995). These programs are most effective in reducing discrimination when they are designed to specifically enhance the 
competencies and thus the potential promotion of disadvantaged groups to line management positions.

Benefits. The elimination of institutional biases is facilitated by making it easier for employees to balance work and family role demands. Family friendly benefits include timebased strategies such as flextime, telecommuting and leave policies; information-based strategies such as referral programs, child and elder care support groups, and help with retirement planning; money-based strategies such as flexible benefits, tuition reimbursement, and benefits for spouses, domestic partners, and dependents; and direct services such as onsite day care, legal and psychological counseling (Button, 2001; Lobel \& Kossek, 1996; Mills, 2000). In addition, policies for scheduling and holidays communicate the extent to which an organization values different religions, and the breadth of accommodation policies for employees with disabilities are critical antecedents of discrimination against disabled workers (Roberts, 1996). It is important to recognize that by addressing only the most visible problems of employees—such as child care—organizations risk discriminating against childless employees or against people with less visible problems such as alcoholism. Therefore, programs that incorporate all kinds of diversity and lifestyles are the most effective at reducing discrimination.

Grievance Procedures. Despite care that is taken in the design and implementation of HR practices, employees may still perceive that they have experienced discrimination. Thus it is important to have grievance procedures in place that give employees an opportunity to voice their concerns to the company and provide an opportunity for conflicts to be resolved internally rather than externally in the court systems (Jackson \& Schuler, 2003). Indeed, the mere presence of grievance systems that overtly offer the possibility to lodge a grievance can help reduce perceptions of inequitable treatment (Gordon \& Bowlby, 1988; Olson-Buchanan, 1996). However, it is important to recognize that the design of grievance systems itself may inadvertently favor certain groups and thus perpetuate discrimination in organizations. For 
example, Rigor (1991) notes that use of grievance systems to report sexual harassment is extremely low due to the fact that sexual harassment policies in organizations have a gender bias and do not reflect women's perceptions of the phenomenon. To reduce discrimination and promote inclusiveness, organizations must create grievance systems that are sensitive to diverse concerns among employees, are structured to encourage diverse employees to file complaints, and provide protection and recourse to the less powerful, lest those employees be labeled "whistle-blowers."

\section{Organizational Climate}

The final organizational-level antecedent to discrimination in our model is organizational climate. Climate is most accurately viewed as one manifestation of the culture (Schneider, 2000) that reflects shared perceptions of the organization's policies, practices and procedures, as well as employees' perceptions of the kinds of behavior that management rewards, expects, and supports (Reichers \& Schneider, 1990). An organization can have multiple climates, each with a particular referent (Schneider \& Reichers, 1983), thus one must speak of a "climate for X" rather than simply referring to "the" organizational climate.

One important type of climate that is highly relevant for discrimination is an organization's diversity climate, for organizations with positive climates for diversity are likely to exhibit lower levels of discrimination due to their heightened sensitivity and commitment to issues having to do with managing a diverse workforce (Cox, 1994). In the present framework, we define Climate for Diversity (CFD) as employees' shared perceptions of the policies, practices and procedures that implicitly and explicitly communicate the extent to which fostering and maintaining diversity and eliminating discrimination is a priority in the organization (Nishii \& Raver, 2003). In practice, when organizations have a positive CFD, all employees are integrated into the fabric of the organization and are encouraged to attain their full potential unhindered by group identities. In such a climate, discrimination should be lower than when the climate for diversity is negative and HR practices are inconsistently enacted, minorities are in 
segregated and non-powerful networks, and prejudicial organizational assumptions and values abound.

Although there has been little empirical work on diversity climates at the organizational level of analysis, there have been a handful of studies that have examined individual level perceptions of climate for diversity and its correlates. The assumption here is that there will be within-organization variability in CFD perceptions, and that it is important to understand the ways in which employees differ in their perceptions, for these perceptions are associated with differential experiences vis-à-vis discrimination in the workplace. Research has found, for example, that diversity climate perceptions vary along gender and racial lines, with women and racioethnic minorities perceiving lower levels of inclusion, bias in informal processes, lost opportunities due to bias, and insufficient attention paid to diversity (Kossek \& Zonia, 1993; Mor Barak, Cherin, \& Berkman, 1998). Further, differential diversity climate perceptions are important because they are related to organizational commitment, job satisfaction, and career satisfaction (Hicks-Clarke \& Iles, 2000). More recently, Nishii and Raver (2003) found that the sharedness of employees' CFD perceptions is based on shared identity (e.g., race and organizational status) rather than formal organizational groupings (e.g., units/divisions) as is often the case with other types of climates (e.g., climate for service), and that clusters of employees with similar perceptions differ in their levels of job satisfaction and organizational commitment. This discussion implies that if diverse employees believe that the organization is discriminatory and report experiences that reflect bias, this is the "reality" about which the organization should be concerned, for employees behave according to their perceptions and attributions (Weick, 1995). Thus, organizational leaders should assess employees' perceptions of discrimination in organizations and pay particular attention to any group differences that arise.

\section{Organizational Consequences of Discrimination}

In this final section, we present some outcomes that may result when organizational diversity has not been effectively managed, and thus discrimination is prevalent. At the 
individual level of analysis, discriminatory behaviors are the primary outcome of interest, yet at the organizational level of analysis, it is the aggregate of these discriminatory behaviors that creates serious and expensive consequences for organizations. As Figure 1 illustrates, negative outcomes of discrimination feed back into the environment and subsequently influence the organizational-level throughputs in a cyclical process.

Perhaps the most tangible consequences of discrimination are the costs associated with lawsuits, grievances and turnover. The legal costs of discrimination can be particularly high, with settlements for discrimination cases often in the tens or hundreds of millions of dollars (King \& Spruell, 2001). In addition to lawsuits, investigations of employee grievances can also be costly, both in terms of personnel time and resources necessary to conduct an investigation (Hauck, 1997). Furthermore, with the high costs of recruiting, selecting, and training replacement employees, turnover associated with perceived bias and discrimination can be extremely costly for organizations (Robinson \& Dechant, 1997).

In addition to these financial costs, there are other consequences of discrimination that may impair organizational effectiveness. The reputation of the organization is likely to be impaired by public awareness of discrimination in that organization (Wentling \& Palmas-Rivas, 1997). An organization's reputation not only influences current employees' commitment and the perceived fulfillment of their psychological contracts, it also influences the organization's ability to attract qualified applicants (Robinson \& Dechant, 1997) and may also influence customers' willingness to purchase products and services (Pruitt \& Nethercutt, 2002). Discrimination may also have implications for the overall quality of the product or service being produced (e.g., Eisenberger, Fasolo \& Davis-LaMastro, 1990). Employees in service organizations tend to treat customers consistently with how they are treated (Schneider, White, \& Paul, 1998), thus employees who are mistreated through discriminatory behaviors may be likely to provide poor customer service. Finally, researchers have proposed and found a link between experiences of discrimination and employees' levels of stress and strain (Gee, 2002; Shaffer, Joplin, Bell, Lau, \& Oguz, 2000; 
Waldo, 1999), which may increase organizations' costs through worker's compensation claims, health insurance, and disability leave (Northwestern National Life Insurance Company, 1991).

\section{Frontiers of Research On Organizational Discrimination}

We have shown that organizational discrimination is the result of multiple interrelated organizational-level processes. That is, throughout our discussion, we have illustrated how organizational structure, culture, leadership, strategy, HR systems, and climate all work together as organizational throughputs to create an environment in which discrimination is either prohibited and sanctioned or subtly tolerated. In this final section, we highlight a number of critical areas for future research on organizational discrimination.

The importance of alignment. In this chapter, we have discussed organizational-level antecedents to discrimination as if they were largely independent. This was done, in part, for ease of presentation. However, existing research on discrimination has, in fact, tended to examine sources of discrimination in isolation of each other. Future research is needed to examine the consequences that the alignment among organizational processes and structures (Delery, 1998) has for levels of organizational discrimination. This is critical because an intervention into a single process or structure is unlikely to effectively reduce organizational discrimination. For example, if top management leaders adopt a strategic business plan that explicitly involves reducing discrimination, but fail to also build a culture of inclusion, show leadership support and accountability for the initiative, and design HR systems that actively seek to promote access and treatment inclusion at all levels, their efforts are likely to be ineffective. Indeed, research may show that the misalignment of organizational processes and structures with respect to discrimination actually produces more discrimination and mistreatment of employees. For example, we would predict that when harassment training is implemented in an organization that has a strong climate that permits harassment, there could be backlash effects, and ultimately higher levels of harassment (Raver \& Gelfand, 2003). Along these lines, it would be useful to examine how individuals perceive the alignment of organizational 
processes and structures vis-à-vis issues of discrimination, and the consequences that such perceptions have for organizations. To the extent that managers perceive that discrimination issues are dealt with idiosyncratically across organizational systems, they will likely feel less accountable and motivated to behave in ways that combat discrimination. Likewise, minorities who perceive that practices are not aligned may be reluctant to use grievance systems to report incidents of discrimination for fear of backlash, even if such systems are technically in place. More generally, research needs to take a systems approach to discrimination wherein the interrelationship between processes and structures is considered to be as important as documenting their independent influence on discrimination.

Cross-Level research. Throughout this chapter, we have presented evidence that organizational processes and structures impact discrimination in organizations. Future research is needed to develop multilevel models that illustrate how such macro-level factors affect lowerlevel phenomena in organizations. Perry et al. (1994) argued that the organizational demography of top management teams as well as aspects of organizational structure affect lower level employees' cognition in ways that can result in discriminatory hiring decisions on the part of those employees; yet there is a dearth of research on such cross-level processes in the field. For example, a lack of structural integration and a climate that permits discrimination is likely to have implications for minorities' cognitive processes and their sensemaking of everyday ambiguous events. As compared to organizations which have a diverse representation of top mangers and a climate for inclusiveness, minorities are likely to feel more "stereotype threat" (Steele, 1997) on a daily basis, and to interpret ambiguous events as discriminatory in nature (Leslie \& Gelfand, 2003). Discriminatory organizational processes and structures are also likely to affect the dynamics of teams. For example, Martins, Milliken, Wiesenfeld, \& Salgado (2003) found that in organizations that are highly homogeneous, teams were much more likely to pay attention to racioethnic category differences, as compared to teams in more heterogeneous organizations. It is even conceivable that macro-level organizational processes may filter down 
to how customers behave toward minorities in organizations, particularly in service firms in which employees and customers are involved in the co-production of the service. Given that climate experiences reported by employees are accurately perceived by customers (Schneider, Bowen, Ehrhart, \& Holcombe, 2000), it is possible that a climate for discrimination within an organization, as perceived by the customers served by that organization, may increase the perceived permissiveness of discriminatory behavior on the part of customers toward boundary role employees. In support of this notion, Gettman, Gelfand, Leslie and Schneider (2003) found that departments that have high levels of sexual harassment also tend to have high levels of customer harassment of employees. While the causal direction of such relationships remains to be examined, it is important that research examine discrimination that that is perpetrated by individuals that are outside of organizational boundaries.

The organization embedded in context. Taking an open-systems perspective, we have argued that the external contexts in which organizations are embedded also affect the dynamics of discrimination in organizations. We briefly discussed a number of environmental inputs into organizations-such as the local context, the political and legal context, and the larger cultural context-that can affect levels of discrimination in organizations. Much research, however, is needed to explore how such extra-organizational forces affect discrimination in organizations. For example, much of the research in this chapter focused on U.S. based organizations, and our discussion implicitly assumed that organizational boundaries were within the United States. Yet with the era of globalization, many U.S. companies now operate globally, and are characterized by complex organizations that cross national borders in the form of multinational companies, international mergers and acquisitions, joint ventures, and international alliances. Accordingly, there is a critical need for research on discrimination in organizations to move beyond the domestic context to incorporate the global context of organizations.

Moving beyond domestic boundaries presents a number of cultural and legal complexities in dealing with discrimination. For example, we previously discussed the importance of building an 
organizational climate and culture that is intolerant of discrimination, of designing HR systems to reflect values for inclusiveness, and of the importance of top management support for a zerotolerance policy on discrimination. Yet a key question is how organizations can create and sustain such processes and structures when operating on foreign soil where there may be different cultural practices, values, and norms regarding discrimination that conflict with those in the U.S. As noted by Cava and Mayer (1993), multinational organizations often feel pressure to follow local norms in the host country in which they are operating, in order to gain a competitive advantage. Many companies may simply "take the line of least resistance" (Hutchings, 1998), causing multinationals to be reluctant to transfer their own practices regarding discrimination to the host country. A critical question then is how U.S. companies, who are attempting to create a global organizational culture, attempt to "negotiate" the culture for intolerance for discrimination that is derived from Westerns practices, values, and laws, with those of other cultures. In some countries, legal restrictions prevent women in the local context from occupying particular jobs (Cava \& Mayer, 1993)—and, in effect, contrary to the U.S. civil rights act, gender can be considered a bona fide occupational qualificiation (BFOQ). Relatedly, while U.S. based employees operating on foreign soil are still technically protected by the civil rights act (Caligiuri \& Cascio, 1998), women and minorities may still face overt and covert discrimination in other cultures. Research has shown that U.S. female expatriates, for example, experience overt prejudice and discrimination from host nationals (Izraeli, Banai, \& Zeira, 1980; Stone, 1991). At the same time, it is also important to examine how cultural constructions of what constitutes discriminatory behavior may vary across cultures. For example, perceptions of what is considered sexual harassment can vary across cultural boundaries (Pryer, DeSouza, Fitness, Hutz, Kumpf, Lubbert, Pesonen, \& Erber, 1997), as can cultural norms for coping with harassment (Wasti \& Cortina, 2002). A critical agenda for discrimination research, therefore, is to understand how to best protect diverse employees operating in discriminatory environments abroad, while at the same time, being culturally sensitive to local definitions and practices. 


\section{Conclusion}

In this chapter, we have argued that discrimination in organizations is a complex, multiply determined phenomenon. We emphasized that organizations need to critically analyze how organizational structures, processes, and practices separately and collectively serve to perpetuate discrimination in organizations, and need to understand how the contexts in which organizations are embedded serve as critical inputs that affect levels of discrimination. It is only by making concerted efforts targeted across the great variety of issues we have identified, by taking a truly systems approach that organizations can best eliminate discrimination. 


\section{References}

Arvey, R.D., Azevedo, R.E., Ostgaard, D.J., \& Raghuram, S. (1996). The implications of a diverse labor market on human resource planning. In E.E. Kossek \& S.A. Lobel (Eds.), Managing diversity: Human resource strategies for transforming the workplace (pp. 5173). Cambridge, MA: Blackwell.

Bennett, R.J. (2002). Cracking the glass ceiling: Factors affecting women's advancement into upper management. Academy of Management Executive, 16, 157-159.

Bernardin, H.J., Hagan, C.M., Kane, J.S., \& Villanova. (1998). Effective performance management: A focus on precision, customers, and situational constraints. In J.W. Smither (Ed.), Performance appraisal: State of the art in practice (pp. 3-48). San Francisco, CA: Jossey-Bass.

Biernat, M., \& Kobrynowicz, D. (1997). Gender and race-based standards of competence: Lower minimum standards but higher ability standards for devalued groups. Journal of Personality and Social Psychology, 72, 544-557.

Blum, T.C., Fields, D.L., \& Goodman, J.S. (1994). Organizational-level determinants of women in management. Academy of Management Journal, 37, 241-268.

Braddock, J.H., III, \& McPartland, J.M. (1987). How minorities continue to be excluded from equal employment opportunities: Research on labor market and institutional barriers. Journal of Social Issues, 43, 5-39.

Brass, D.J. (1985). Men's and women's networks: A study of interaction patterns and influence in an organization. Academy of Management Journal, 28, 327-343.

Brief, A.P., Dietz, J., Cohen, R.R., Pugh, S.D., \& Vaslow, J.B. (2000). Just doing business: Modern racism and obedience to authority as explanations for employment discrimination. Organizational Behavior and Human Decision Processes, 81, 72-97.

Burke, R.J., McKeen, C.A., \& McKenna, C. (1993). Correlates of mentoring in organizations: The mentor's perspective. Psychological Reports, 72(3), 883-896.

Button, S.B. (2001). Organizational efforts to affirm sexual diversity: A cross-level examination. Journal of Applied Psychology, 86, 17-26.

Caligiuri, P. M., \& Cascio, W. F. (1998). Can we send her there? Maximizing the success of Western women on global assignments. Journal of World Business, 33, 394-417.

Campion, M.A., Outtz, J.L., Zedeck, S., Schmidt, F., Kehoe, J.F., Murphy, K.R., \& Guion, R.M. (2001). The controversy over score banding in personnel selection: Answers to 10 key questions. Personnel Psychology, 54, 149-185.

Carnevale, A.P., \& Stone, S.C. (1995). Diversity beyond the golden rule. Training \& Development, 48, 22-37.

Cava, A., \& Mayer, D. (1993). Gender discrimination abroad. Business and Economic Review, 40, 13-16.

Catalyst. (1993). Successful initiatives for breaking the glass ceiling to upward mobility for minorities and women. New York: Catalyst.

Conway, J.M., Jako, R.A., \& Goodman, D.F. (1995). A meta-analysis of interrater and internal consistency reliability of selection interviews. Journal of Applied Psychology, 80, 565579.

Cox, T.H., Lobel, S., \& McLeod, P. (1991). Effects of ethnic group cultural difference on cooperative versus competitive behavior in a group task. Academy of Management Journal, 34, 827-847.

Cox, T., Jr. (1994). Cultural diversity in organizations: Theory, research, and practice. San Francisco: Berrett-Koehler Publishers.

Cox, T.H., \& Blake, S. (1991). Managing cultural diversity: Implications for organizational competitiveness. Academy of Management Executive, 5, 45-56. 
Davidson, O.B., \& Eden, D. (2000). Remedial self-fulfilling prophecy: Two field experiments to prevent Golem effects among disadvantaged women. Journal of Applied Psychology, 85, 386-398.

Delaney, J.T., \& Lundy, M.C. (1996). Unions, collective bargaining, and the diversity paradox. In E.E. Kossek \& S.A. Lobel (Eds.), Managing diversity: Human resource strategies for transforming the workplace (pp. 245-272). Cambridge, MA: Blackwell.

Delery, J.E. (1998). Issues of fit in strategic human resource management: Implications for research. Human Resource Management Review, 8, 289-310.

DiMaggio, P.J. and Powell, W.W. (1983). The iron cage revisited: Institutional isomorphism and collective rationality in organizational fields. American Sociological Review, 48, 147-160.

Donaldson, T. \& Preston, L.E. (1995). The stakeholder theory of the corporation: Concepts, evidence and implications. Academy of Management Review, 20, 65-91.

Douglas, C., Ferris, G.R., Buckley, M.R., \& Gundlach, M.J. (2003). Organizational and social influences on leader-member exchange processes: Implications for the management of diversity. In G.B. Graen (Ed.), Dealing with diversity. Greenwich, CT: Information Age Publishing.

Dvir, T., Eden, D., \& Lang Banjo, M.L. (1995). Self-fulfilling prophecy and gender: Can women be Pygmalion and Galatea? Journal of Applied Psychology, 80, 253-270.

Eisenberger, R., Fasolo, P., \& Davis-LaMastro, V. (1990). Perceived organizational support and employee diligence, commitment, and innovation. Journal of Applied Psychology, 75, 5159.

Fadil, P.A. (1995). The effects of cultural stereotypes on leader attributions of minority subordinates. Journal of Managerial Issues, 7, 193-208.

Gagliardi, P. (1986). The creation and change of organizational cultures: A conceptual framework. Organization Studies, 7, 117-134.

Gee, G.C. (2002). A multilevel analysis of the relationship between institutional and individual racial discrimination and health status. American Journal of Public Health, 92, 615-623.

Gettman, H., Gelfand, M., J., Leslie, L., \& Schneider, B. (2003). Relationships between internal and external sexual harassment. Paper submitted for the Annual Conference of the Society for Industrial and Organizational Psychology.

Gordon, M.E., \& Bowlby, R.L. (1988). Propositions about grievance settlements: Finally, consultation with grievants. Personnel Psychology, 41, 107-123.

Gottfredson, L.S. (1992). Dilemmas in developing diversity programs. In S.E. Jackson \& Associates (Eds.), Diversity in the Workplace (pp. 279-305). New York: Guilford Press.

Hanover, J.M.B., \& Cellar, D.G. (1998). Environmental factors and the effectiveness of workforce diversity training. Human Resource Development Quarterly, 9, 105-125.

Hauck, V.E. (1997). Arbitrating race, religion, and national origin discrimination grievances. Westport, CN: Quorum Books.

Heilman, M.E., Block, C.J., \& Lucas, J.A. (1992). Presumed incompetent? Stigmatization and affirmative action efforts. Journal of Applied Psychology, 77, 536-544.

Hickman, J., Tkaczyk, C. Florian, E., Stemple, J. , \& Vazquez, D. (2003). 50 best companies for minorities. Fortune, 148(1), 103-109.

Hicks-Clarke, D., \& Iles, P. (2000). Climate for diversity and its effects on career and organizational attitudes and perceptions. Personnel Review, 29, 324-346.

Hiller, N.J., \& Day, D.V. (2003). LMX and teamwork: The challenges and opportunities of diversity. In G.B. Graen (Ed.), Dealing with diversity. Greenwich, CT: Information Age Publishing.

Hough, L.M., Oswald, F.L., \& Ployhart, R.E. (2001). Determinants, detection and amelioration of adverse impact in personnel selection procedures: Issues, evidence and lessons learned. International Journal of Selection and Assessment, 9, 152-194. 
House, R.J., Hanges, P.J., Javidan, M., Dorfman, P.W., \& Gupta, V. (In press). Culture, leadership, and organizations: The GLOBE study of 62 cultures. Sage Publications.

Hutchings, K. (1998). Good corporate citizens or perpetrators of social stratification? International business in Malaysia. In R. M. Afzalur \& R. T. Golembiewski (Eds.) Current topics in management (Vol 3, pp. 345-364). Stamford, CT: JAI Press.

Ibarra, H. (1993). Personal networks of women and minorities in management: A conceptual framework. Academy of Management Review, 18, 56-87.

Ilgen, D.R., \& Youtz, M.A. (1986). Factors affecting the evaluation and development of minorities in organizations. Research in Personnel and Human Resources Management, 4, 307-337.

Izraeli, D. N., Banai, M., \& Zeira, Y. (1980). Women executives in MNC subsidiaries. California Management Review, 23, 53-63.

Jackson, S.E. (1992). Preview of the road to be traveled. In S.E. Jackson \& Associates (Eds.), Diversity in the Workplace (pp. 3-12). New York: Guilford Press.

Jackson, S.E., \& Alvarez, E.B. (1992). Working through diversity as a strategic imperative. In S.E. Jackson \& Associates (Eds.), Diversity in the Workplace (pp. 13-29). New York: Guilford Press.

Jackson, S. E., \& Schuler, R. S. (2003). Managing Human Resources through Strategic Partnerships ( $8^{\text {th }}$ Edition). Cincinnati: South-Western College Publishing.

James, E.H. (2000). Race-related differences in promotions and support: Underlying effects of human and social capital. Organization Science, 11, 493-508.

Joplin, J.R.W., \& Daus, C.S. (1997). Challenges of leading a diverse workforce. Academy of Management Executive, 11, 32-47.

Kahn, J. (2001). Diversity trumps the downturn. Fortune, 144(1), 114.

Kanter, R.M. (1977). Men and women of the corporation. New York: Basic Books.

Katz, D., \& Kahn, R.L. (1978). The Social Psychology of Organizations (2 ${ }^{\text {nd }}$ Edition). New York: Wiley.

Kelley, S.W. (1993). Discretion and the service employee. Journal of Retailing, 69, 104-126.

Kim, S.S., \& Gelfand, M.J. (2003). The influence of ethnic identity on perceptions of organizational recruitment. Journal of Vocational Behavior.

King, A.G., \& Spruell, S.P. (2001). Coca-Cola takes the high road. Black Enterprise, 31(7), 29.

Klimoski, R., \& Donahue, L. (1997). HR strategies for integrating individuals with disabilities into the work place. Human Resource Management Review, 7, 109-138.

Kossek, E.E., \& Zonia, S.C. (1993). Assessing diversity climate: A field study of reactions to employer efforts to promote diversity. Journal of Organizational Behavior, 14, 61-81.

Kram, K.E. (1985). Mentoring at work: Developmental relationships in organizational life. Glenview, IL: Scott, Foresman, and Co.

Kravitz, D.A., Harrison, D.A., Turner, M.E., Levine, E.L., Chaves, W., Brannick, M.T., Denning, D.L., Russell, C.J., \& Conard, M.A. (1996). Affirmative action: A review of psychological and behavioral research. Bowling Green, $\mathrm{OH}$ : Society for Industrial and Organizational Psychology.

Ledvinka, J., \& Scarpello, V.G. (1991). Federal regulation of personnel and human resource management (Kent human resource management series). Boston: PWS Publishing Co.

Leslie, L. M., \& Gelfand, M. J. (2003). Contextual influences on the attribution to discrimination process. Paper submitted for the Annual Conference of the Society for Industrial and Organizational Psychology.

Levitin, T., Quinn, R.P., \& Staines, G.L. (1971). Sex discrimination against the American working women. American Behavioral Scientist, 15, 238-254.

Lobel, S.A., \& Kossek, E.E. (1996). Human resource strategies to support diversity in work and personal lifestyles: Beyond the "family-friendly" organization. In E.E. Kossek \& S.A. Lobel (Eds.), Managing diversity: Human resource strategies for transforming the workplace (pp. 221-244). Cambridge, MA: Blackwell. 
Loden, M., \& Rosener, J.B. (1991). Workforce America! Managing employee diversity as a vital resource. Homewood, IL: Business One Irwin.

Martin, J. (2002). Organizational culture: Mapping the terrain. Thousand Oaks, CA: Sage.

Martins, L. L, Milliken, F. J., Wiesenfeld, B. M., \& Salgado, S. R. (2003). Racioethnic diversity and group members' experiences; the role of the racioethnic diversity of the organizational context. Group and Organization Management, 28, 75-106.

Milliken, F. J., \& Martins, L. L. (1996). Searching for common threads: Understanding the multiple effects of diversity in organizational groups. Academy of Management Review, 21, 402-433.

Mills, K.I. (2000). GLBT employees make gains in workplaces nationwide. Diversity Factor, 9(1), 8-11.

Mischel, W. (1976). Towards a cognitive social model learning reconceptualization of personality. In N.S. Endler \& D. Magnusson (Eds.), Interactional psychology and personality (pp. 166-207). New York: Wiley.

Mischel, W. (1977). The interaction of person and situation. In E. Magnusson \& N.S. Endler (Eds.), Personality at the crossroads. Hillsdale, NJ: Erlbaum.

Mor Barak, M.E., Cherin, D.A., \& Berkman, S. (1998). Organizational and personal dimensions of diversity climate: Ethnic and gender differences in employee perceptions. Journal of Applied Behavioral Sciences, 31, 82-104.

Morrison, A.M. (1992). The new leaders: Guidelines on leadership diversity in America. San Francisco: Jossey-Bass.

Morrison, A.M., \& Von Glinow, M.A. (1990). Women and minorities in management. American Psychologist, 45, 200-208.

Nieva, V.F., \& Gutek, B.A. (1980). Sex effects on evaluation. Academy of Management Review, 5, 267-276.

Nishii, L.H., Mayer, D., Goldstein, H., \& Dotan, O. (2004). Diversity and bottom-line performance: The moderating role of leader-member exchange. Paper to be presented at the Society for Industrial and Organizational Psychology annual conference in Chicago, IL.

Nishii, L.H., \& Raver, J.L. (2003). Collective Climates for Diversity: Evidence from a Field Study. Paper presented at the Society for Industrial and Organizational Psychology annual conference, Orlando, Florida.

Northwestern National Life Insurance Company. (1991). Employee burnout: America's newest epidemic. Minneapolis, MN: Author.

Oerton, S. (1994). Exploring women workers' motives for employment in cooperatives and collectives. Journal of Gender Studies, 3, 289-297.

Olson-Buchanan, J.B. (1996). Voicing discontent: What happens to the grievance filer after the grievance? Journal of Applied Psychology, 81, 52-63.

O'Reilly, C.A., Williams, K.Y., \& Barsade, S. (1998). Group demography and innovation: Does diversity help? Research on Managing Groups and Teams, 1, 183-207.

Perry, E.L., Davis-Blake, A., \& Kulik, C.T. (1994). Explaining gender-based selection decisions: A synthesis of contextual and cognitive approaches. Academy of Management Review, 19, 786-820.

Peters, T.J., \& Waterman, Jr., R.H. (1982). In search of excellence: Lessons from America's best-run companies. New York: Harper \& Row.

Prasad, P., Mills, A.J., Elmes, M., \& Prasad, A. (1997). Managing the organizational melting pot: Dilemmas of organizational diversity. Thousand Oaks, CA: Sage.

Pruitt, S.W., \& Nethercutt, L.L. (2002). The Texaco racial discrimination case and shareholder wealth. Journal of Labor Research, 13, 685-693. 
Pryer, J., DeSouza, E. R., Fitness, J., Hutz, C., Kumpf, M., Lubbert, K., Pesonen, O., Erber, M. W., (1997). Gender differences in the interpretation of social-sexual behavior: A crosscultural perspective on sexual harassment, Journal of Cross-Cultural Psychology, 28, 509-534.

Ragins, B. R., \& Cornwell, J. M. (2001). Pink triangles: Antecedents and consequences of perceived workplace discrimination against gay and lesbian employees. Journal of Applied Psychology, 86, 1244-1261.

Ragins, B.R., \& Sundstrom, E. (1989). Gender and power in organizations: A longitudinal perspective. Psychological Bulletin, 105, 51-88.

Raver, J. L., \& Gelfand, M. J. (2003). Beyond the individual victim: The impact of sexual harassment on team processes and performance. Paper presented at the Annual Conference of the Academy of Management, Seattle, WA.

Reichers, A.E., \& Schneider, B. (1990). Climate and cultures: An evolution of constructs. In B. Schneider (Ed.), Organizational Climate and Culture (pp. 5-39). San Francisco: JosseyBass.

Riger, S. (1991). Gender dilemmas in sexual harassment policies and procedures. American Psychologist, 46, 497-505.

Roberts, K. (1996). Managing disability-based diversity. In E.E. Kossek \& S.A. Lobel (Eds.), Managing diversity: Human resource strategies for transforming the workplace (pp. 310331). Cambridge, MA: Blackwell.

Robinson, G., \& Dechant, K. (1997). Building a business case for diversity. Academy of Management Executive, 11, 21-31.

Ryan, A.M., \& Ployhart, R.E. (2000). Applicants' perceptions of selection procedures and decisions: A critical review and agenda for the future. Journal of Management, 26, 565606.

Sathe, V. (1985). How to decipher and change corporate culture. In R.H. Kilmann, M.J. Saxton, R. Serpa, \& Associates (Eds.), Gaining Control of the Corporate Culture (pp. 230-261). San Francisco: Jossey-Bass.

Schein, E.H. (1971). The individual, the organization and the career: A conceptual scheme. Journal of Applied Behavioral Science, 7, 401-426.

Schein, E.H. (1985). Organizational culture and leadership. San Francisco: Jossey-Bass.

Schneider, B. (2000). The psychological life of organizations. In N.M. Ashkanasy, C.P.M. Wilderom, \& M.F. Peterson (Eds.), Handbook of Organizational Culture and Climate (pp. xvii-xxii). Thousand Oaks, CA: Sage.

Schneider, B., Bowen, D. E., Ehrhart, M. G., \& Holcombe, K. M. (2000). The climate for service: Evolution of a construct. In N. M. Ashkanasy, C. P. M. Wilderom, \& M. F. Peterson (Eds.) Handbook of organizational culture and climate (pp. 21-36). Thousand Oaks, CA; Sage.

Schneider, B., \& Reichers, A.E. (1983). On the etiology of climates. Personnel Psychology, 36, 19-39.

Schneider, B., White, S., \& Paul, M. C. (1998). Linking service climate and customer perceptions of service quality: Test of a causal model. Journal of Applied Psychology, 83, 150-163.

Schneider, K.T., Hitlan, R.T., \& Radhakrishnan, P. (2000). An examination of the nature and correlates of ethnic harassment experiences in multiple contexts. Journal of Applied Psychology, 85, 3-12.

Seidel, M.L., Polzer, J.T., \& Stewart, K.J. (2000). Friends in high places: The effects of social networks on discrimination in salary negotiations. Administrative Science Quarterly, 45, $1-24$.

Shaffer, M.A., Joplin, J.R.W., Bell, M.P., Lau, T., \& Oguz, C. (2000). Gender discrimination and job-related outcomes: A cross-cultural comparison of working women in the United States and China. Journal of Vocational Behavior, 57, 395-427. 
Siehl, C. \& Martin, J. (1988). Measuring organizational culture: Mixing qualitative and quantitative methods. In M. Jones, M. Moore, \& R. Snyder (Eds.), Inside organizations: Understanding the human dimension (pp. 79-104). Newbury Park, CA: Sage.

Staw, B.M., Sandelands, L.E., \& Dutton, J.E. (1981). Threat-rigidity effects in organizational behavior: A multilevel analysis. Administrative Science Quarterly, 26, 501-524.

Steele, C. M. (1997). A threat in the air: How stereotypes shape intellectual identity and performance. American Psychologist, 52, 613-629.

Stone, R., (1991). Expatriate selection and failure. Human Resource Planning, 14, 9-18.

Stoner, C.R., \& Russell-Chapin, L.A. (1997). Creating a culture of diversity management: Moving from awareness to action. Business Forum, 22(2/3), 6-12.

Thomas, D.A. (1993). Racial dynamics in cross-race developmental relationships. Administrative Science Quarterly, 38, 169-194.

Triandis, H.C., Kurowski, L.L., \& Gelfand, M.J. (1994). Workplace diversity. In H.C. Triandis, M.D. Dunnette, \& L.M. Hough (Eds.), Handbook of industrial and organizational psychology, Vol. 4 (2 ${ }^{\text {nd }}$ Edition; pp. 769-827). Palo Alto, CA: Consulting Psychologists Press.

Trice, H.M., \& Beyer, J.M. (1991). Cultural leadership in organizations. Organization Science, 2, 149-169.

Tsui, A.S., \& O'Reilly, C.A. (1989). Beyond simple demographic effects: The importance of relational demography in superior-subordinate dyads. Academy of Management Journal, 32, 402-423.

U.S. Bureau of Labor Statistics (1999). BLS releases new 1998-2008 employment projections, News release USDL-99-339. http://www.bls.gov/opub/working/sources.htm

U.S. Department of Labor Office of Federal Contract Compliance Programs. (1995). OFCCP glass ceiling initiative: Are there cracks in the ceiling? Washington, DC: Office of Federal Contract Compliance Programs, U.S. Department of Labor.

U.S. Equal Employment Opportunity Commission. (2001). Job patterns for minorities and women in private industry (EEO-1). http://www.eeoc.gov/stats/jobpat/2001/national.html

U.S. General Accounting Office. (2002). A new look through the glass ceiling: Where are the women? http://www.house.gov/dingell/dingellmaloneyreport.pdf

Waldo, C.R. (1999). Working in a majority context: A structural model of heterosexism as minority stress in the workplace. Journal of Counseling Psychology, 46, 218-232.

Wasti, A., \& Cortina, L. (2002). Coping in context: Sociocultural determinants of responses to sexual harassment. Journal of Personality and Social Psychology, 83, 394-405.

Weick, K.E. (1995). Sensemaking in Organizations. Thousand Oaks, CA: Sage.

Wentling, R.M., \& Palma-Rivas, N. (1997). Diversity in the Workforce: A Literature Review (MDS-934). Berkeley, CA: National Center for Research in Vocational Education.

Whitely, W., Dougherty, T.W., \& Dreher, G.F. (1991). Relationship of career mentoring and socioeconomic origin to manager's and professionals' early career progress. Academy of Management Journal, 34, 331-351.

World Values Study Group. (1994). World values survey. Ann Arbor, MI: Inter-university consortium for political and social research.

Yukl, G., \& Van Fleet, D.D. (1992). Theory and research on leadership in organizations. In M.D. Dunnette \& L.M. Hough (Eds.), Handbook of industrial and organizational psychology, Vol. 3 ( $2^{\text {nd }}$ Edition; pp. 147-197). Palo Alto, CA: Consulting Psychologists Press.

Zohar, D. (2000). A group-level model of safety climate: Testing the effect of group climate on microaccidents in manufacturing jobs. Journal of Applied Psychology, 85(4), 587-596. 